\title{
The Empirical Stance vs. The Critical Attitude ${ }^{1}$
}

\section{Darrell Patrick Rowbottom}

\author{
Department of Philosophy \\ University of Durham \\ E-mail: d.p.rowbottom@durham.ac.uk
}

\begin{abstract}
Van Fraassen has recently argued that empiricism can be construed as a stance, involving commitments, attitudes, values, and goals, in addition to beliefs and opinions. But this characterisation emerges from his recognition that to be an empiricist cannot be to believe, or decide to commit to belief in, a foundational proposition, without removing any basis for a non-dogmatic empiricist critique of other philosophical approaches, such as materialism.

However, noticeable by its absence in Van Fraassen's discussions is any mention of Bartley's 'pancritical rationalism', for Bartley offers a cohesive argument that genuine dogmatism lies precisely in the act of commitment to an idea. The consequence of denying this, he thinks, is an opening of the floodgates to irrationalism: if to rely on reasoned argument in decision-making is fundamentally an act of faith, then there is a tu quoque - "I simply have a different faith" - that may be employed by those who wish to shield their views from criticism.

This raises the following question: why should it be any less dogmatic to adopt particular commitments, attitudes, values, and goals, rather than a particular belief or opinion, come what may? And if Bartley is right that there is only one non-dogmatic attitude - the critical attitude - then why might this not be adopted by an empiricist, a materialist, a metaphysician, or anyone else?
\end{abstract}

\section{Introduction}

The Empirical Stance has considerable scope, yet it clearly builds upon Van Fraassen's earlier work, in particular The Scientific Image. Its central question is clear: 'What is empiricism, and what could it be?' (Van Fraassen, 2002:xiii). And while some of the tactics that Van Fraassen employs in order to answer this should be familiar by now for example, he maintains the view that explanatory power should only be construed as a pragmatic virtue for theories, that the only forms of possibility and necessity are verbal, and that there is a radical distinction between acceptance and belief - his overall strategy has developed considerably. Most noticeably, he now has metaphysics firmly in his sights, whereas beforehand, he has only hinted at such antipathy. ${ }^{2}$

1 I am grateful to E.J.Lowe, Sarah Aiston, audiences at the University of Durham and the PSSA Conference 2005, and two of the journal's anonymous referees, for their comments on earlier versions of this piece. I am particularly grateful to Otávio Bueno for a prolonged, and extremely enlightening, exchange on The Empirical Stance.

2 See the introduction to Van Fraassen (1980), where it is implied that Aristotelian philosophy inhibited progress in the Middle Ages, and that there is strong similarity between the reasons for which nominal- 
Early on, Van Fraassen recasts empiricism as a 'stance' in response to problems that he identifies with classical understandings of empiricism. Yet he goes on to suggest it might be compared with other alleged stances, in particular 'The Materialist Stance', and found to be superior. So on the basis of a perfunctory reading, it might be thought that 'stances' are doing rather a lot of work: not only do they provide the basis for a more robust form of empiricism, but also a metaphilosophical apparatus for debates between empiricists and non-empiricists. The suspicion that this is simply 'too good to be true', for the empiricist, might then arise.

But would this be right? What I should like to determine in this paper is not only the actual role that 'stance' plays in Van Fraassen's arguments, but also what role it ought to play, if any. In order to determine the former, which I attempt first, I adopt a charitable approach, and suggest that the antecedent characterisation is quite unfair. However, I then continue by suggesting that 'stance' ought not to have an important role to play either in defending empiricism, or in enabling an empiricist critique of metaphysics (or materialism). To illustrate this, I offer a novel characterisation of 'stance', through which it emerges that Van Fraassen's arguments are only effective against particular forms of metaphysics (and materialism), which share similar components. In closing, I formulate an empiricism that is actually less dogmatic than Van Fraassen's 'Empirical Stance', but which subordinates empiricism to Bartley's 'pancritical rationalism'. I therefore urge that it is really the latter that does the important work, and that all empiricists ought to be pancritical rationalists, if they are to avoid basing their positions on faith alone.

\section{The Invocation of 'Stance'}

In attempting to establish what empiricism might be, Van Fraassen first considers it as a historical movement, and draws the conclusion that it is characterised by 'a recurrent rebellion against the metaphysicians' (Van Fraassen, 2002:36). However, since this is one of the points at issue herein, it cannot bode well for us to accept this, as it stands. Instead, this claim might be moderated somewhat, and we might accept, pending further investigation, that empiricism is at least characterised by its opposition to certain forms of metaphysics.

More revealing and cogent, however, is his subsequent analysis of what empiricism cannot be. For he argues that the empiricist cannot engage in a critique of metaphysics - or for our purposes, any form of metaphysics - if she accepts a 'Principle Zero' such that (Van Fraassen, 2002:41):

For each philosophical position $\mathrm{X}$ there exists a statement $\mathrm{X}+$ such that to have (or take) position $\mathrm{X}$ is to believe (or decide to believe) that $\mathrm{X}+$.

Why? Because to hold that there is a factual thesis that is not only immune to empiricist criticism, but is also the foundation of the empiricist's attack on metaphysics, is problematic; this, for it might be open to metaphysical criticism. ${ }^{3}$ And although the empiricist might confess to having made a leap of faith, the metaphysician with an opposing foundational claim might confess to the same, and a stalemate would ensue. The price of shielding one's position from criticism on the basis of an appeal to faith is

ists oppose metaphysical realism, and those for which empiricists oppose scientific realism. See also the opening chapters of Van Fraassen (1989), and Van Fraassen (1991).

3 Along related lines, Ewing (1951:ch.2) argues that 'the proposition that there can be no synthetic a priori propositions would itself, if justified, have to be a synthetic a priori proposition ...' 
that one allows others to shield their positions on precisely the same basis. In the words of Bartley (1962:103-104):

In sum, the belief that rationality is ultimately limited, by providing an excuse for irrational commitment, enables a Protestant, or any other irrationalist, to make an irrational commitment without losing intellectual integrity. But at the same time, anyone who makes use of this excuse may not, in integrity, criticize the holder of a different commitment. One gains the right to be irrational at the expense of losing the right to criticize. One gains immunity from criticism for one's own commitment by making any criticism of commitments impossible ... Moreover if everyone has to be a subjectivist, there is a sort of consolation: nobody can look in from the outside. Everyone is alone, inside his own mirror cage, staring at his own face. No wonder the existentialists are bored ... The fact remains that anyone who is bored of being bored must answer the $t u$ quoque.

So how might we view a philosophical position if 'Principle Zero' is violated? The answer: as a 'stance', which involves beliefs and opinions, but also 'involves a great deal more, will not be identifiable through the beliefs involved, and can persist through changes of belief' (Van Fraassen, 2002:62). And this knits nicely with Van Fraassen's suggestion that the history of ideas plays an important role in giving us an orientation: 'In every century we must reinterpret ourselves to ourselves. We do not come into our century with a tabula rasa' (xvii). It is also clear, even from his brief initial discussion, that while any 'stance' is supposed to be radically dependent on value-judgements and attitudes, 'toward life, love, and laughter' (62), it is also supposed to be possible to compare 'stances' on a principled intersubjective basis. For example, in comparing the 'stance' of materialism with that of empiricism, Van Fraassen thinks it is illuminating to examine how proponents of each approach (empirical) science.

Thankfully, there is a wealth of recent material available in order to inform the exploration of 'stance', which I will return to later. But here, in focusing on the reason for which Van Fraassen introduces the notion, I want to concentrate on the alleged significance of Principle Zero. For as Teller (2004:160-162) points out - and unwittingly follows Bartley in so doing - it would seem that Van Fraassen's argument is not sufficient to suggest that there ought not to be any $\mathrm{X}+$ to the $\mathrm{X}$ of a position, but rather that:

[T]here can be no such proposition that is held or maintained in a certain way, held as a "thesis" ... [S] omeone believes a statement as a thesis if they also believe, or expect, or even just hope that, in the context under consideration, the statement is susceptible to rational support of the kind that makes it uniquely defensible as opposed to its contraries ... The "susceptible to rational support" may be only "in principle", may be hopelessly out of practical reach.

Teller's suggestion is clearly that it might be perfectly acceptable to believe in whatever foundational proposition(s) one wishes - issues concerning synchronic coherence aside - provided one is not attached to them in a potentially epistemically unwise (or even flatly self-deceptive) sense. That is, a sense which I shall endeavour to explicate further in my discussion of Popper's 'critical attitude', and Bartley's 'pancritical rationalism', later in the paper. I will also urge that Teller's mention of 'the context under consideration' is of paramount import, because if one is to be a non-dogmatic empiri- 
cist, then one must be receptive to transcendent, as well as immanent, criticism of one's empiricism. In other words, that there is a sense in which an empiricist is obliged to be willing to be dissuaded from empiricism, by someone who disagrees on the very standard of what is admissible (or permissible) in a critical discussion.

So I will contend that Rorty (2002) is absolutely right to ask, in his review of The Empirical Stance: 'Is there a difference that makes a difference between assuming a stance and acquiring a set of beliefs, except perhaps for what Peirce called "a certain contrite fallibilism"?' Not, as we shall see, because there is no difference: Van Fraassen has some clear ideas about what is, and is not, involved in taking a stance. But rather because it is plausible that there would seem to be no difference that makes a difference to the prospects of empiricism. It is only in so far as 'The Empirical Stance' is supposed to involve a deep fallibilism, and thus a derivative willingness to be open-minded, that it ought to be invoked by Van Fraassen, with respect to his ultimate end: to achieve an empiricism that is not self-refuting, in the fashion that he takes naïve empiricism, or what Lipton (2004) and Teller (2004) call 'doctrine empiricism', to be.

In fact, in accepting that 'Principle Zero' ought to be abandoned only in the sense that none of us should just commit ourselves to, rather than merely be convinced of, the truth of particular propositions, it does not follow that we need invoke the notion of 'stance' . Enter the 'critical attitude' promoted by Popper, of which Rorty's mention of Peirce is rather suggestive (Freeman and Skolimowski 1974:515):

Like Peirce, Popper also on occasion labels his philosophy "fallibilism." But a much happier designation for identifying the methodology of both Peirce and Popper is found in Popper's inspired phrase, "conjectures and refutations," which comes much closer to capturing the essence of Scientific Method. ${ }^{4}$

Before continuing in this vein, however, there is a pressing issue to which we should return: 'metaphysics' for Van Fraassen. We need also to understand what precisely he takes himself to be arguing against, and what the arguments are that he employs, before we can determine whether these also have, or ought to be thought to have, any relationship to his invocation of 'stance' .

\section{The Argument Against 'Metaphysics'}

In order to understand Van Fraassen's argument against 'metaphysics', we first need to understand what he takes 'metaphysics' to refer to. He inveighs against, variously, 'a seventeenth-century style of metaphysics' (Van Fraassen, 2002:4), '[Quinean] analytic ontology' (11), and 'materialism' (49-61). But hidden away in a footnote is a more substantive definition of that which he opposes (231):

The type of metaphysics to which I refer, and which I take to be the enterprise engaged in by, for example, Descartes and Leibniz, is characterized by the attempted construction of a theory of the world, of the same form as a fundamental science and continuous with (as extension or foundation of) the natural sciences.

Yet this is still rather vague. And Van Fraassen's statement in the introduction, 'I do not reject all metaphysics' (xvii), might seem curious, given his apparent association

4 Note that Popper does not believe in a scientific method, above and beyond that of philosophy. See the introduction to Popper (1983), and section 5 of this paper. 
of 'metaphysics' with 'trivial pursuits' (30) at the end of chapter one, and thenceforth. On the one hand, his point might be understood as this: many activities that involve 'puzzle-solving' (in something like Kuhn's sense) are trivial, but we need not reject them; all metaphysics is 'word play', but need not be avoided as long as it is not accompanied by 'false consciousness' (e.g. the belief that it is disclosing some special knowledge about the actual). On the other, it might be thought that he owes us an explication of what sort of metaphysics can be meaningful, and useful, according to one who has an 'Empirical Stance'. Besides the recognition that Van Fraassen is opposed to philosophical approaches that are too respectful of the content of natural science, rather than its methodology, we are at an impasse. Needs must we look beyond The Empirical Stance, to not only his subsequent, but also his antecedent, work.

In his earlier scholarship, however, Van Fraassen offers a characterisation of empiricism that seems far removed from his present one (Van Fraassen 1989:8): 'By empiricism I mean the philosophical position that experience is our source of information about the world, and our only source.' For here, of course, we have a substantive thesis - an $\mathrm{X}+$ to the $\mathrm{X}$ of empiricism, if 'Principle Zero' holds - with which many a metaphysician, realist or idealist, would want to strongly disagree. Now we are told that this is wrong - or characterises a naïve form of empiricism - and that the situation is far less clear. Either one is supposed to be able to adopt an 'Empirical Stance' without believing (or perhaps even having the opinion) that 'Experience is our source of information about the world, and our only source', or without holding it as a 'thesis' in Teller's sense, explained beforehand. Hence, the possibility of there being metaphysicians who are also empiricists, or empiricists who are pro-metaphysics, would not seem to be precluded. For instance, it is unclear whether the position of Lowe involves (or could involve) an 'Empirical Stance' (Lowe, 1998:22-23):

[M]etaphysics by itself can only tell us what is metaphysically possible, not which of various alternative metaphysical possibilities actually obtains ... the conclusions of metaphysical arguments will often have the form of conditional statements, which are themselves shown by such arguments to be unconditionally true. For instance, such a conclusion might be that if time is real, then some persisting substance must exist. The fact that metaphysics often delivers conclusions of this form in no way conflicts with the claim that the primary object of metaphysics is to establish the metaphysical possibility of various states of affairs and that it does not, in general, tell us by itself that such-and-such a state of affairs actually obtains ... How, then, are we to form rational judgements as to which of various metaphysically possible alternatives do actually obtain? In a word: by experience. Knowing how the world could be in respect of its fundamental structure, we must judge as best we can how it is by determining how well our experience can be accommodated with this or that metaphysical possibility as regards that structure. This may appear to give metaphysical theorizing a status similar to that of scientific theorizing, but the similarity is only superficial. A judgement that the world actually exhibits a given metaphysical feature - for instance, that it contains substances or that time is real - will indeed be an a posteriori judgement, being responsive to the evidence of experience. But the content of the judgement still retains its modal character as expressing a genuine metaphysical possibility, albeit one judged now to be actualised. 
Lowe's position is particularly interesting to contrast with Van Fraassen's, since whereas the former is founded on (a belief in) deep de re modality - on the notion that there are broadly logical, in addition to narrowly and strictly logical, necessities - the latter would seem to involve (a belief in) the dictum that all necessity is (merely) verbal (Van Fraassen 1977). In fact, Van Fraassen (2004b:186) draws our attention to 'a profound sense - typical of the empiricist tradition - of utter contingency in nature ... that finds expression in ... rejection of any and all rationalist groping for natural necessities (let alone informative a priori truths).' Yet, while the scope of modality is an extremely interesting issue, it remains unclear that it ought to have such a great epistemological impact. For instance, presumably to be a constructive empiricist is to be an empiricist, and might - although it need not - involve taking the Empirical Stance. Yet by the admission of Monton and Van Fraassen (2003:406): '[it] is certainly much easier for a modal realist to be a constructive empiricist than anyone else' . Hence, it is somewhat of a mystery how Van Fraassen (2004b:186) can claim 'Certainly the content of a particular empiricist's philosophical stance must be precisely what characterizes his/her position. Thus it must entail the relevant beliefs (for example, that there are no laws of nature)', since this would mean that there could be constructive empiricists who are not empiricists, in virtue simply of their believing in laws of nature.

One suspects that this problem arises because too much burden is being placed upon poor little 'empiricism' - in addition, I will argue, to unlucky 'metaphysics' - and because we are never directly told what it is supposed to be. It $i s$ characterised, but in a disjointed fashion that is liable to lead to inconsistencies, or at least reasonable confusion, such as that explained above. It is difficult to see the wood for the trees. And since according to Lowe's account, experience is extremely important as a source of knowledge - indeed, the ultimate purpose of metaphysical theorising is to enable us to get at how the world actually is, via experience - we might be forgiven for thinking that there is a genuine sense in which it is that of an empiricist. ${ }^{5}$ That is, unless being 'anti-metaphysics' is necessary in order to be an empiricist, which is surely a thesis that is quite disputable, if it is not to beg the question, given that 'empiricism' has an actual history. To put the point plainly: if Van Fraassen can dissociate himself from historically significant aspects of 'empiricism' such as associationism (and the affiliated belief in sense impressions) and yet remain an 'empiricist', then why can one not dissociate oneself from its 'anti-metaphysics', and yet remain an 'empiricist' ? As we shall see, this question becomes even more pressing when it is admitted that to be an empiricist is not merely to adopt a particular set of beliefs, opinions, or propositional attitudes. It is not just a verbal quibble, but a genuine dispute about what is at the heart of 'empiricism': about the extent to which it involves a deep respect for, and involvement with, sensory experience (and/or its objects, construed perhaps as the $\phi \alpha \imath v o ́ \mu \varepsilon v o \varsigma$, in Empiricus' sense). ${ }^{6}$ (That is, as opposed to a rejection of the possibility of, or any value whatsoever in, non-sensory experience.) Notice, here, the guarded language I use: how I intimate that we might be able to admire sensory experience, in-

5 In fact, his view is not only perfectly consistent with, but also suggestive of, a claim such as: 'Experience is our most important source of information about the (actual) world.'

6 Needs must I skirt around the issue of theories of perception, but I agree with Ladyman (2000) that Van Fraassen seems to be a direct realist. On this note, it is worth noting that Lowe (1981) favours (a form of) indirect realism; in this respect, then, he is arguably closer to being an 'empiricist', historically speaking, than Van Fraassen. 
deed revel in it, and thereby engage with the world in a different fashion to those who do not, without needing to commit, in any sense, to the truth of a particular proposition, or propositions. This is important since Van Fraassen (2004b: 173) wants to have it, with respect to doctrines such as 'Experience is our source of information about the world, and our only source', that: '[T]he commitment [to empiricism] is not based on that belief; instead there is a kind of pragmatic incoherence in having such a commitment while denying or expressing disbelief or doubt with respect to that statement.' I will confess that I find the notion of 'pragmatic incoherence' a little difficult to grasp pragmatism seems to be assumed as a background here, where perhaps it ought not to be - but take the point to be along the following lines. Even if someone denies that doctrine, they might nevertheless be an empiricist, and engage with the world as an empiricist; the denial of said doctrine would then be incoherent only in so far as they would be failing to recognise their implicit sympathy to it, but not the rational necessity of their committing to belief in it. This could be through self-deception, inter alia.

But back to 'metaphysics' for Van Fraassen, and let us first look to his Laws and Symmetry, and second to his Quantum Mechanics: An Empiricist View, before moving on to his recent articles. In the former, we find the claim that 'the end of the eighteenth century marks a great turning-point in philosophy' (Van Fraassen 1989:8), which involved a desire, on the part of empiricists, to separate science from not only theology, but also 'metaphysics' . Van Fraassen is highly dubious that 'reason can bring us to logical ... certainty of truths that transcend experience' (8). And moreover, we find a clue as to what form of metaphysics may be acceptable to him. One that bears surface similarity to the Kantian conception, in so far as it only allows for (9):

[T] he critical archaeology of ideas to uncover the actual presuppositions in actual history of science, plus the analysis of possible presuppositions that could constitute a foundation for science.

In the latter, we find a further development of this position, whereby Van Fraassen expresses his dislike for scientism, according to which science 'is elevated (?) to the status of metaphysics' (Van Fraassen 1991:17). Predictably, the point seems to be that obsession with the content of contemporary science, if that content is taken to disclose the truth or approximate truth about the 'way the world is' (viz. what is actually the case), is inadvisable: as such, his arguments against scientific realism and metaphysics of a certain sort do seem to come together. But notice that being interested in the content of science in another way is perfectly permissible (Van Fraassen 1991:4):

When we come to a specific theory, the question: how could the world possibly be the way this theory says it is? concerns the content alone. This is the foundational question par excellence, and it makes equal sense to the realist and empiricist alike.

Now this is a striking statement, because Van Fraassen clearly wants to have it that it is perfectly reasonable to be interested in, and even carefully examine, the content of contemporary science. What is wrong is to be an epistemic realist in the mould of those that march under the flag of 'scientific realism'; as Psillos (1999:xix) puts it, to regard 'mature and predictively successful scientific theories as well-confirmed and approximately true of the world.' Yet Van Fraassen does not tell us that a metaphysician need be a scientific realist, presumably because this is not the case! As such, it seems strange that the objection to the use of abduction with respect to the non-ob- 
servable is still the primary line that van Fraassen employs in order to address 'the metaphysician', in The Empirical Stance.

He asks (Van Fraassen, 2002:16), 'Where is the metaphysician who shows us how likely it is that inference to the best explanation in ontology will lead to true conclusions?' But all one need say in reply is, "Where is the empiricist who shows us how likely it is that inference to the best explanation with respect to appearances will lead to true conclusions about future (or potential past) appearances?" (And if there is no necessity in nature, then why should there be any in sensory experience, or with respect to the interaction of the objects thereof?) It remains unclear that abduction is vital for metaphysics, or indeed for anything else, and if Van Fraassen's 'anti-metaphysical' position relies on the idea that metaphysics is (or particular forms thereof are) impossible without abduction, then he owes us an argument that he does not seem to have yet provided. After all, to make a demand for explanation, and then to outline possible explanations, is not to select one of those explanations on the basis that it is 'best' . Furthermore, the subsequent choice to select one that is 'best' could very well be a purely pragmatic move, rather than a truth-conducive one, in science as well as in metaphysics. From ' $p$ is the best explanation of $q$ ', and ' $q$ ', ' $p$ is true' or ' $p$ is probably true' might not follow. But from ' $p$ is the only explanation of $q$ ', and ' $q$ ', ' $p$ is true' would seem to. This, for the latter case would seem to involve $p \leftrightarrow q, q$, rather than just $p \rightarrow q, q$, as premises. Having said this, it must nonetheless be noted that according to Van Fraassen (2004a:128), empiricist critiques of metaphysics involve 'a rejection of demands for explanation at certain crucial points'. So a complete response to his charge, which is surely based on his earlier account of explanation (Van Fraassen 1980:ch.5), is still outstanding.

This will have to wait until another time, though, since Van Fraassen has another critique of metaphysics that demands attention. Specifically, this is that: "[T]he interpretation of a theory targets how nature is represented in that theory, while the metaphysician targets (or purports to target) the nature that the theory represents.' (Van Fraassen, 2004b:180). Now to this it must be said, first, that if we could only ever 'target' how nature is represented, as opposed to nature (or aspects thereof), then we could never get started in inquiry. This, since any 'representation' would surely have to be a part of reality - in a non-specialist sense of 'reality' - in order for it to serve as a target! Second, that in so far as there is an implicit suggestion, here, that a scientist can somehow target nature, whereas a metaphysician cannot (without relying on science), this seems implausible. In particular, even if Van Fraassen is correct that it is only via attempts to construct empirically adequate theories that we can engage with nature - effectively, that we only interact directly with observables, or the observable part of nature, from an epistemic perspective - then metaphysical inquiry with respect to that domain would still seem not only possible, but also potentially useful. Along these lines, Ladyman (2004:135) suggests, 'Metaphysical theories are connected with experience, albeit more tenuously than concrete realistic interpretations of bits of science.' Yet I do not think he goes far enough, in so far as there are clear examples of metaphysical issues that are just about as 'connected with experience' as one can get. Consider the question of why a glass does not become part of a table when it is placed upon it, as a nail might when it is hammered in to strengthen a weakening joint. Or the problem of whether it is really my watch that is being returned to me, when the watchmaker has removed its original hour hand and replaced it with another. 
The point is that it would be a bad presupposition that metaphysicians need only, or must only, look to science (or the special sciences). In fact, even if metaphysics were neither a foundation, nor an extension, of science, it need not follow that it would therefore be valueless, or even of less value than science. From a practical perspective, it is true that we would not have television sets without science. (And it is such considerations that motivate pragmatists to value science so highly.) But it would be a mistake to conflate technological developments with the scientific activity that serves to partially enable them. Nowhere in physics, or chemistry, or any other special science, is there a theory about how to make television sets, or even a complete list of instructions for doing so. And if anything, we are repeatedly reminded of the insufficiency of even our most advanced theories, taken alone, when it comes to solving practical problems. The sum total of physics does not tell us how to make a comfortable shoe using only simple (e.g. Roman) tools, let alone how to construct a fighter jet using all the modern resources at our disposal. So it remains unclear that metaphysics - or at least metaphysical assumptions - are not required in such extra-scientific contexts. Of course, this is not to say that science cannot inform metaphysical theorising (or vice versa), or that it ought not to.

A related matter of considerable import, particularly if we are to attempt to allow for value judgements as part of philosophical positions, is that of the relative value of scientists - or more properly scientific activity - in the context of the community at large, or even just the community of inquirers. Ladyman (2004:136) asks: '[W]hy not allow the empiricist to have a pragmatic commitment to metaphysical theories, and to entertain them as ways the world might be ... ?' And Van Fraassen (2004b:181) grants that if metaphysical speculation 'has great heuristic and inspirational value, let's encourage scientists to so far forget themselves as to constantly engage in it.' Yet while this is not an unreasonable response, on the face of it, we must be careful not to assume that special scientists can simply 'do metaphysics' at a whim, or imply that to do metaphysics well is easy, and does not require special training, or at least understanding that must be acquired (and sustained) by hard intellectual toil. In fact, to allow this would be to smuggle in what is plausibly a caricature based precisely on an empiricist value judgement: that soi disant 'metaphysicians' are idle dreamers, with minimal interest in the (actual) world about them, and less still in positively contributing to society.

Needless to say, I do not accept such a picture. Furthermore, I do not think it can be the place of every scientist, say, to grow and prepare her own food, teach her children, look after her ageing parents, and so forth. In so far as food is important for all in society, we ask, "How many of us ought to be farmers?" And in so far as inquirers are important to society, we ought to ask, "To which problems should their intellectual efforts be directed?" But in doing so, we need to understand the internal dynamic of the community of inquirers. For instance, in so far as mathematics is required for (good) natural science, it might follow that we need dedicated mathematicians, even if natural science is more valuable at the level of the intersection of the community of inquirers with other such communities. If a dictum such as 'natural scientific problems take precedence' is not to be taken merely to be an underhanded repudiation of metaphysical activity, then what is needed is a strong argument that what metaphysicians do, qua metaphysicians, is largely useless. And even then, it would seem it could still be conceded that some metaphysicians are useful. So in this light, any suggestion that metaphysics ought to be utterly abandoned would seem to be implausibly strong. Imagine the villagers who chase out one of their blacksmiths for working only on discovering 
new alloys, when weapons are urgently required for a forthcoming confrontation. And imagine then the dismay of the other blacksmiths, who are hoping for a new alloy in order that they might craft superior weapons, which would ultimately be of greater benefit to the villagers. In short, Lipton (2004:153) is right to draw our attention to the fact that, 'Kuhn suggests how a divergence in epistemic policies performs an essential epistemic function, by enabling the scientific community to hedge its epistemic bets.' But in addition to this, divergence in practices might fulfil a similar function, inside as well as outside of science. So even if it is not quite right to say that 'stances' are akin to epistemic policies, as I shall explain shortly, to the extent that they involve particular ways of doing things, or prompt indulgence in particular sorts of activity, it might be a boon that there be considerable variance. Moreover, tolerance might be recommended on principled epistemic grounds, with respect to (many of) the practices so encouraged, in spite of the 'stance(s)' responsible for motivating them.

It is also worth putting all this in actual socio-economic context. It is hardly the case that our youth are clamouring to become metaphysicians, or that physics departments are being closed down in order to make way for departments of philosophy, let alone shiny new departments of metaphysics! And from this point of view, Van Fraassen's focus on metaphysics seems rather curious. After all, surely empiricism might be better negatively characterised by its opposition to mysticism, superstition, cultism, and fundamentalism? And from the perspective of the world at large, are these not greater threats? Even if we restrict our attention to what is occurring within academia, there are arguably more 'worthy' targets for the empiricist elsewhere, as the infamous Sokal hoax would seem to have clearly illustrated. Yet as Beller (1998) argues, it is plausible that the mystical pronouncements of the architects of quantum theory - such as Bohr, Heisenberg, and Börn - have contributed to such misuse, and misunderstanding, of science. ${ }^{7}$ So why not ally empiricism with a rejection of any ultimate appeal to, or uncritical respect for, authority?

But let us pause and take stock. What we have found, I think, is that Van Fraassen's arguments are really against particular forms of metaphysics - 'naïve metaphysics' would seem to be a suitable moniker - involving the view that reason alone can lead us to the absolute (or perhaps, even more perniciously, certain) truth about the way things actually are. Such naïve metaphysics is even worse, he thinks, when it involves the hijacking of an alleged 'method of science' - namely abductive reasoning - which its practitioners appeal to in order to defend the results of the enterprise. For instance, in the work of some materialists, he detects a deference to science, qua authority, which he finds distasteful (Van Fraassen, 2002:63): 'the belief that the scientific description of the world is true, in its entirety or near enough, and at least a strong inclination towards completeness claims for the content of certain sciences. "This is true, and nothing else is true" would express such claims.' But of course any given metaphysician, or indeed any given materialist, need not have that belief. To which I might add that this metaphysician finds the aforementioned belief to be just as repugnant as

7 In a subsequent letter to the same periodical (August 1999, Physics Today), Sokal and Bricmont express considerable sympathy: 'Beller observes, correctly, that famous physicists such as Bohr, Born, and Pauli engaged at times in dubious (to say the least) extrapolations of ideas from quantum physics to politics, psychology, philosophy, and religion. She also notes that these writings were sometimes treated by physicists with excessive reverence, rather than being subjected to the critical analysis they deserve. Finally, she observes, again correctly, that the popular writings of these and other physicists - in which the foundational issues associated with quantum mechanics are often grossly oversimplified - served as one source of inspiration (among many others) for postmodernist musings about science.' 
Van Fraassen does, and for several shared reasons: I too reject the epistemic thesis, but not the semantic thesis, of so-called 'scientific realism' (Psillos, 1999:xix). ${ }^{8}$

Here we reach the nub of this section, which sets the stage for what follows: if empiricism can help itself to 'stance' in order to avoid requiring a 'Principle Zero' (in the relevant sense explained by Teller), then why can materialism not do the same? Can it be right that what is good for the goose is not good for the gander? And might there not be some individuals who can be correctly described as 'materialists', but will say "On the off-chance that the scientific description of the world is true, in its entirety or near enough, let us see what would be the case"? Who show no deference to science, yet nevertheless have an interest in its proclamations, and have no false consciousness about the project that they are undertaking? Who will tell us that they just so happen to be 'materialists', but do not think that anyone is rationally compelled to be a 'materialist' ? Stay tuned for the answers to all these questions, and more.

\section{Voluntarism, Empiricism, and the Conceptualisation of 'Stance'}

Van Fraassen (2002:48) writes: '[I]f empiricism is a stance, its critique of metaphysics will be based at least in part on something other than factual theses: attitudes, commitments, values, goals.' Yet what we have seen is that this claim is somewhat misleading, at least taken out of context. In particular, if empiricism is a 'stance' but there are also metaphysical 'stances', then empiricism might only involve a critique of particular forms of metaphysics, viz. particular 'metaphysical stances' . (It is often unclear whether Van Fraassen really wants to attack 'metaphysics' qua activity, or just those implicit policies that he thinks are liable to underlie the activity. So 'metaphysical stances' might be better replaced by 'metaphysicians' stances', as we shall see.) To which we might add that it is unclear that there need be just one 'Empirical Stance': there may be a variety of empirical 'stances', some of which might also be criticisable on the basis of Van Fraassen's 'Empirical Stance' . In other words 'The Empirical Stance' might provide a means by which to offer a critique of 'The Naïve Empirical Stance', as well as 'The Naïve Metaphysical Stance', and so forth.

We now find ourselves with a problem that I touched upon in the previous section. What is the scope of a 'stance' ? For example, if Van Fraassen has 'The Empirical Stance', then how close does my stance have to be to his, in terms of beliefs, opinions, attitudes, commitments, values, and goals, in order for it to be that same 'Empirical Stance'? It would seem that 'The Empirical Stance' is being used as an umbrella term for a number of possible individual philosophical positions (personal stances), but unless we have a fixed reference point, it is entirely unclear how we are to evaluate what does and does not count as 'The Empirical Stance'. Worse, it might seem that how we choose to group sets of personal stances is a matter of convention. Why should Van Fraassen's personal philosophical position be the benchmark for what counts as 'The Empirical Stance'? And if it is not, then what is the benchmark? Could someone possibly show us what it is?

Of course, if to be an empiricist is not to hold that any particular proposition is true - to hold to an E+ for the E of empiricism - then it would seem that two empiricists could differ on all their factual theses, yet nonetheless share 'The Empirical Stance' .

8 'Important similarities between the views of Popper and Van Fraassen, which I will only be able to touch on here, are: (a) each rejects the idea that scientific theories can gain degrees of confirmation (with respect to truth, even if not empirical adequacy); and (b) each forswears the claim that a contemporary theory is typically approximately true. 
This is wholly implausible (or would, at the very least, involve considerable 'pragmatic incoherence' on one, or both, of their parts), but as we have seen in section 2 , what is really important is that there is no E+ held as a 'thesis' in the sense explained by Teller (2004). So as Ladyman (2004:139) suggests, one might argue that, ' $[\mathrm{B}]$ elieving some $\mathrm{X}+$ is at least a necessary condition for adopting a stance even if it is not sufficient.' And Van Fraassen (2004b:190, f.4) now seems to agree, if only by way of alleged clarification, despite his previous statement that (2002:46): '[T]here cannot be such a proposition as E+' . The problem is solved, in principle if not in practice, because by specifying beliefs typical of empiricists, we may come to understand the stance that underlies those beliefs, however imperfectly. But a smaller problem, which remains, is that once we set a benchmark for a given 'Stance', we will have to decide some sort of cut-off point, at which a personal stance is sufficiently distant to no longer (nominally) be a variant of said 'Stance' . The most we can say, so far, would seem to be that (Van Fraassen, 2004b:174): '[S]haring the same stance... entails sharing certain attitudes, typically including certain beliefs, but allows for many relevant differences as well.'

Here it is worth emphasising that Van Fraassen takes a particular aspiration for epistemology to be central to the empiricist tradition: for it to tackle the problems concerning scientific revolutions, and conversions. Thus, he proposes to take a permissive view of rationality, which he refers to as voluntarism, such that (Van Fraassen, 2004a:129): " "[W]hat is rational is whatever is rationally permitted": rationality is bridled irrationality.' He appeals to the 'boringly repetitive failures of the idea of Induction and similar rule-governed concepts of rational opinion and management' (Van Fraassen, 2004b:182) by way of support, but without even a single mention of Popper. ${ }^{9}$ As I intend to explain in the next section, this is intellectually curious given not only that Popper was a voluntarist, but also that his arguments against so-called inductive inferences - precisely, that these are not rationally compelling - have not been widely accepted. For example, Williamson (2005a:12) advocates Objective Bayesianism, according to which, '[O]nly one value for $p(\mathrm{v})$ will be deemed rational on the basis of an agent's background knowledge ... [T]wo agents with the same background knowledge must adopt the same probabilities as their rational degrees of belief.' Therefore, it is extremely disappointing of Van Fraassen (2004b:179) to claim: 'The most concise way to indicate the empiricist tradition's tendencies in epistemology is once again to point to the sorts of metaphysics it rejects.' This is like saying that the most concise way to indicate what a carnivore tends to eat is to point to chocolate ice creams! Being concise is not only a matter of being brief, but also of being comprehensively so, after all. Besides which, any suggestion that intellectualism is incompatible with voluntarism should, as I hope to show, be resisted.

At this juncture, it will prove useful for us to draw upon the notion of an epistemic policy, which is presented by Teller (2004) as a functional characterisation of 'stance', and which 'provides valuable insight into the concept', according to Van Fraassen (2004b:174). On the surface, the idea is deceptively simple, yet Teller provides an extensive list of how one might characterise a policy, and how these characterisations might also hold for stances: policies are expressions or implementations of values; pol-

9 N.B. By 'Induction', Van Fraassen (2004b: 182) means: 'the putative recipe or rules that spell out a consequence relation that goes beyond logical consequence, and delimits the precise conclusions one must believe (and believe no more than) on the basis of given evidence, on pain of irrationality.' He does not mean 'forming opinions that go beyond our evidence' (and neither, I will argue, does Popper). 
icies can be argued for or against; everyone has a policy; and so forth. I cannot do full justice to his discussion, here, but it has three aspects that I want to cover. The first is that Teller distinguishes between explicit stances, on the one hand, and implicit stances, on the other. The former involve what is explicitly formulated, whereas the latter can involve 'practices... learned and accepted without critical examination... exercised unreflectively... that [nonetheless] function as epistemic guides' (Teller, 2004: 165). But in response it might be urged that a policy is usually taken to be explicit, such that one might sign up to it (according, perhaps, to one's own interpretation), although it might very well be advocated by one who takes a particular position. So I join Van Fraassen (2004b: 178) in thinking that 'stance' must be closer to the implicit notion. As such, he admits that 'The Empiricist Stance' would have been a better name for his recent book, and suggests that 'The Empirical Stance' would be best left to refer to an explicit policy which empiricists - those with empiricist stances - might advocate. (In fact, Teller (2004: 168) accurately surmises: "Perhaps "stance" better than "policy" connotes implicit as well as explicit modes.') Van Fraassen (2004b: 179) is also quick, and quite right, to emphasise that an epistemic policy is not an epistemological position. Hence, one might have a stance without having the faintest idea that there are epistemological positions, whereas formulating or supporting a policy would seem to have to be, or at least typically be, an intentional action.

Second, we should note that Teller (2004:166) urges that a policy is not true or false, but rather well or ill-advised; similarly, Lipton (2004:149) thinks that, 'Somebody who makes the wrong choice of stance is unwise, but not irrational.' However, this presumably comes about since 'rational' has acquired a rather technical sense through its use in the subjective interpretation of probability, according to which an agent is rational just if her degrees of belief do not violate the appropriate mathematical axioms. ${ }^{10}$ But I contend that this technical sense cannot just be assumed, since it is highly dubious that the subjective interpretation is sufficient to explain what it is for us to really be rational, in the everyday sense of 'reasonable' . Consider that all epistemic probabilities - but perhaps not aleatory probabilities - are fundamentally conditional, as Keynes (1921:6-7) forcefully argues. The question arises as to whether 'background knowledge', so often invoked by Bayesians, ought really to be construed just as 'background information', and it is unclear that the answer lies in the affirmative. Let me put it this way: are we really going to allow that a machine which merely assigns coherent evaluations of the extent to which one set of information is contained by another, when provided with such sets, is rational? I am afraid that this idea seems utterly bizarre, and would urge that it is only in virtue of the fact that our 'background knowledge' is more than a collection of propositional entities that we are capable of being rational. To which I might add that there are presumably rational hope-making processes, fear-making processes, and so forth, which can clearly not be accounted for by any presently available theories of probability. I do not think that this is just a verbal issue, at root. Rather it is a genuine disagreement about the scope of rationality, for as Ladyman (2004:142) also suggests, along a closely related line, '[V]oluntarism seems to be a capitulation of reason to instrumental rationality. It is surely part of a rational agent's obligations to have realistic expectations of his or her actions.' The issue is one of 'direction of fit', and it remains unclear why understanding how things are (and might be) is sufficient to enable a reasonable interaction with our surroundings, particularly with respect to our fellows: indeed, surely it is the case that we seek to un-

10 See, for instance, the discussion of the Ramsey-de Finetti theorem in Gillies (2000: 53-65). 
derstand how we would prefer for things to be, for ethical reasons or otherwise, as well as how we would prefer for things not to be. In the terms in which Macleod (1986: 59) puts this, I am therefore in favour of a 'type 3' analysis of 'rationality', in contrast to the 'type 1' and 'type 2' analyses which seem to have been favoured in classical epistemology:

Theories (Type 1 theories, let us call them) for which it is beliefs and belief alone to which terms like rational and irrational are properly applicable will be very different, certainly in scope and probably also in structure, from (Type 2) theories for which actions and decisions can also be said to be rational and irrational. And both will be different from (Type 3) theories, which seem to make room in addition for rational appraisal of an agent's desires and preferences and of the ends, ideals, and principles associated with them.

Now it could be contended, quite reasonably, that 'stance' is actually a means by which to widen the scope of rationality, and that this is really what Van Fraassen intends with his voluntarism. But notice that if a 'type 3' analysis is correct, then we have to admit that there might be flatly irrational, rather than merely unwise, stances. ('The Nazi Stance', taken in historical context, springs to mind.) Of course, this is not to presume that there is only one rational stance, although it might very well be the case that all rational stances share a particular component (or components). Lipton (2004:155) writes, '[T] he crucial question is whether principles of rationality determine the stance: the traditionalist says yes, the voluntarist says no.' But he neglects the middle ground, since the principles of rationality might partially determine the stance, in so far as they determine the rationally permissible set of stances, given an appropriate context.

This brings me on to the third, and final, issue: that of what I shall call stance voluntarism, which ought not to be confused with epistemological voluntarism (to which I refer simply as 'voluntarism' ). For although Van Fraassen (2004b:175) claims, '[A] stance, like a policy or strategy, is something one can adopt or reject', this is actually a rather contentious claim, provided 'adopt or reject' are construed in an intentional sense. In saying this, I have in mind the thesis of doxastic involuntarism, advocated by Alston (1989:115-142), to which a direct analogue might be made. To what extent can it be right that one can actually select one's stance, if at all? And could Van Fraassen adopt 'The Intellectualist Stance', say, through simple 'force of will' ? Of course, advocating a policy, say an explicit manifesto commitment of a political party, is a rather simple intentional action. Adopting that policy, or implementing it, is typically similarly achievable, albeit after hermeneutic appraisal. Yet in the implicit sense of 'policy' that is closer to capturing the notion of 'stance', the situation would seem to be quite different. For instance, how could one intentionally change one's stance, if one didn't realise what that stance was? And even if one is aware of one's own stance, to what extent can its distinctive components be altered at a whim, even with the benefit of deep reflection? If Van Fraassen (2004a:128) is correct not only that stances 'may include some factual beliefs', but also that '[O]ne is generally less committed to a policy than a stance' (Van Fraassen, 2004b:191, f.14), then stance involuntarism would seem to be strongly motivated. Yet, I wish to motivate stance voluntarism, since I disagree with Van Fraassen (2004b:176-177) that,

[A] stance is not a state: the term "stance" has its own connotations of commitment and intention: specifically, the commitment to preserve oneself in that 
very stance ... There is a pragmatic inconsistency in "I am committed to doing $\mathrm{x}$ but not committed to maintaining this commitment."

I am not entirely sure what 'pragmatic inconsistency' is supposed to be, and how it relates to 'pragmatic incoherence', which was mentioned earlier. But nevertheless, this claim seems to be patently false. If I am committed to meeting you for dinner next week, but you phone me to cancel because one of your relatives has just passed away, then surely it would be ridiculous to suggest that I ought to be committed to maintaining the original commitment to meet you for dinner, on pain of being inconsistent; that I ought to urge you nevertheless to meet me for dinner - so as to allow me to maintain my commitment to meet you for dinner - if I am not to be 'pragmatically inconsistent' . On the contrary, there would seem to be no inconsistency, pragmatic or otherwise, in simply discarding the commitment. Now I suppose Van Fraassen might rejoin by giving a different example, say on the question of whether one would allow oneself to be brainwashed, given the understanding that this would 'remove' a commitment. But this is actually rather different: to do one's best to fulfil one's commitment is not to do one's best to preserve that commitment, and in any event, the commitment would arguably remain despite the brainwashing. For understanding that one has a commitment is not the same as having that commitment, and striving to remain aware of one's commitment is not the same as striving to maintain that commitment. Furthermore, to return to the initial example, if you phone me back an hour later in order to ask me whether I would still meet you for dinner, only to be informed that I now have different plans, you ought not to feel that you have the right to rebuke me for refusing, let alone to accuse me of inconsistency! As such, I take it that a stance is a state, and is one that we can (and can be willing to), under the correct circumstances, exercise a considerable degree of control over. In particular, I would urge that we can prepare ourselves to change stance, say as a result of a critical discussion on which stance it is best to adopt, provided we adopt the critical attitude to which I shall turn in short order.

Beforehand, in order to bolster the notion of stance voluntarism, I want to examine a closely related issue. Can it be right that attitudes, commitments, values, and goals, are actually independent of beliefs and opinions? Or as a matter of fact, is the situation really much more complicated? Is it possible, even in principle, for me to share (or to have shared) no beliefs or opinions with Van Fraassen, yet nonetheless adopt exactly the same attitudes, commitments, values, and goals? It would seem not, and that the '[V]arious ingredients cannot be hygienically disentangled and separated.' (Van Fraassen, 2004b:176). Hence, it might seem that a personal stance is really composed of a particular set of propositional attitudes (beliefs, hopes, fears, and so forth), along with a particular mode of engagement. ${ }^{11}$

Fig.1 (see next page) might result from an unimaginative and ungenerous reading of The Empirical Stance, but the model in fig.2 would seem to constitute some sort of improvement, provided stances are to be construed as states. And notice that both the figures are supposed to depict individual, personal, stances. A wider 'Stance' (capital S), such as 'The Empirical Stance', would then be formed by a set of personal stances (qua states). In other words, if $\mathbf{E}$ is 'The Empirical Stance', then this might be the set $\{\mathbf{s} 1, \mathbf{s} 2, \mathbf{s} 3, \ldots \mathbf{s} \mathbf{N}\}$; if I happen to have the personal stance $\mathbf{s 1}$, then this counts as hav-

11 Although Van Fraassen (2004b: 175) writes, 'to love something or someone, to be contemptuous or enamoured: these attitudes cannot be equated with propositional attitudes', he provides no argument to this effect. 
Fig.1 - Simple Model of 'stance'

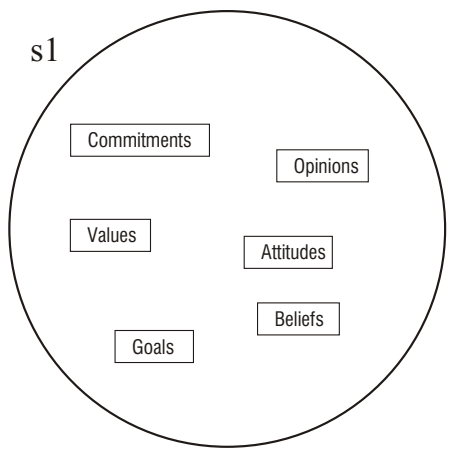

Fig. 2 - Improved Model

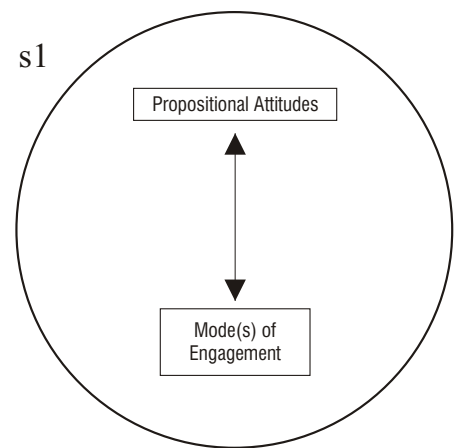

ing 'The Empirical Stance', since $\mathbf{s} \mathbf{1}$ is a member of $\mathbf{E}$. Of course, we are also left with the option of saying that there are personal stances that are members of more than one wider 'Stance' . And perhaps this is what we ought to expect: for instance, one might have 'The Critical Stance' (C), while also having 'The Empirical Stance' (E), but one might also have $\mathbf{C}$ without having $\mathbf{E}$. The situation could be as depicted below, in fig.3:

Fig. 3 - Potential Relationship between Two 'Stances'

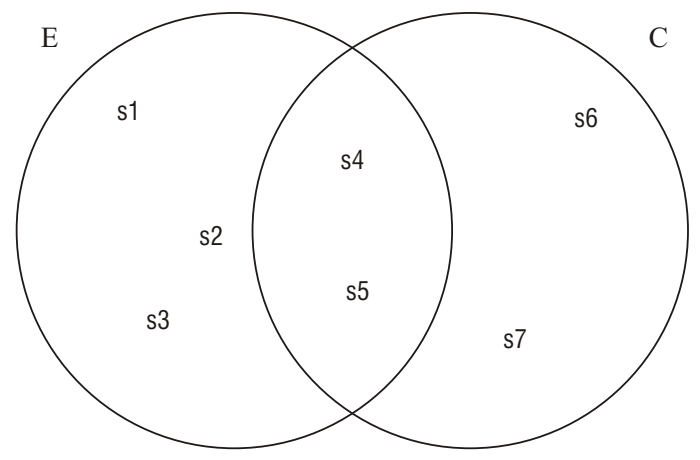

Now putting problems with infinities aside - and it is plausible that there are an infinite number of personal stances that constitute, say, 'The Empirical Stance' - it might be reasonable to suggest that one might identify Stances on the basis of modes of engagement which do not bear any strong bidirectional relationship to propositional attitudes. True, it might be that one cannot achieve these modes of engagement (or initially adopt them) without having one of a particular set of propositional attitudes, but they might be resistant (to a greater or lesser degree) to any future changes in propositional attitudes, once they are adopted. So one could say that all members of $\mathbf{E}$ involve one and the same mode of engagement. Likewise, for all the members of $\mathbf{C}$. Notice, of course, that the mode of engagement will plausibly have a strong effect on how the 
propositional attitudes actually change. How could $\mathbf{E}$ and $\mathbf{C}$, say, overlap? The answer would lie in the fact that modes of engagement can have different scopes, such that they do not necessarily preclude one another.

But is the notion of a 'mode of engagement' not just as vague as that of a 'stance' ? I take the answer to lie in the negative in so far as we are all familiar with the idea that different people have different approaches to the world (and/or particular sorts of situation), which they are sometimes capable of moving between. A classic distinction, employed by St. Teresa of Avila in The Way of Perfection, is between the active and contemplative. Furthermore, the idea of such approaches captures neatly the idea of a posture, without needing to encompass that of a vantage point, thereby enabling easy disambiguation between these two aspects of 'stance', according to Van Fraassen (2004b:174). This is important since the fact that two individuals differ in posture might reflect that they differ in vantage point, although it need not. And in saying this, I do not want to suggest that one's posture never has an effect on one's vantage point. For instance, an active social posture might lead to a more optimistic outlook than a passive (and contemplative) introverted one. Indeed, the way in which we judge the significance of our own actions in a wider context is clearly affected, albeit indirectly, by our posture.

Moreover, such a notion is supportive of the notion of stance voluntarism. For it is a reasonably common view that certain individuals have a disposition for engaging in one particular fashion in a given context - say an active one, as opposed to a passive one - but that they can nevertheless have some level of direct control of how they do, in fact, engage. By contrast, the idea that one has direct control over one's vantage point - as opposed to indirect control, via the adoption of differing modes of engagement (or postures) - seems much more controversial. In fact, it is just as implausible to suggest that one can spontaneously decide not to be unhappy at witnessing a terrible disaster as it is that one can spontaneously decide not to believe that one is witnessing said disaster. One might listen to uplifting music in order to alter one's mood, or one might visit a hypnotist in order to alter one's belief that a terrible disaster had occurred, but such changes would be via indirect mechanisms, as explained by Steup (2000).

\section{The Critical Attitude, Pancritical Rationalism, and Non-Dogmatic Empiricism}

Having gone to considerable effort to understand and elucidate Van Fraassen's line against particular forms of metaphysics, to identify said forms, and to provide an understanding of how all this relates to the notion of 'stance', I have set the stage for my final contention. To put the cart before the horse, this is that in order for empiricism to be non-dogmatic, it must involve a critical attitude - or what might be called a critical mode of engagement - with respect to a particular domain. However, I contend that, since this attitude is characteristic of Bartley's pancritical rationalism, it is really this that can solve the problem of 'Principle Zero' for empiricism, which Van Fraassen introduces 'stance' in order to address. Moreover, I urge that pancritical rationalism provides a broader form of voluntarism than that which Van Fraassen holds is required for empiricism, but also suggests a neater solution to the problem of conceptual change in scientific revolutions, which he identifies as crucial for the empiricist to tackle. In fact, I argue that it is just in so far as 'An Empiricist Stance' shies away from pancritical rationalism that it is dogmatic, and that given this, Van Fraassen's 'Empirical Stance' remains dogmatic. 
In order to introduce the idea of the critical attitude, and its putative significance, let me first use the words of Popper (1968:94-95):

[W] hat characterizes the scientific approach is a highly critical attitude toward our theories rather than a formal criterion of refutability: only in the light of such a critical attitude and the corresponding critical methodological approach do 'refutable' theories retain their refutability ... [T] he demarcation between science and metaphysics is a special case of the wider problem of demarcating criticizable from non-criticizable theories ... the latter problem is at any rate the more general one.

Now by 'criticizable', here, we must note that Popper surely meant 'criticizable on the basis of sensory experience', which he would have cashed out as 'criticizable on the basis of basic (or observation) statements' . (All too often, the 'by sensory experience' clause is assumed in his writing.) Further, there might be some confusion about the scope of 'metaphysics' for Popper, but his overarching approach seems to be summed up rather well by one of his most vociferous, yet also most careful, critics (O' Hear, 1980:111):

Rationality ... consists primarily in eliminating errors and learning from them. This process is not peculiar to empirical science, nor is empirical science furthered by empirical testing alone, although it is undoubtedly true that change because of empirical testing is one important mark of the scientific and serves to distinguish it from conservative and empirically closed systems such as African magic ... the importance of distinguishing between science and non-science seems to diminish in comparison with the importance of distinguishing what counts as a critical as opposed to a dogmatic approach in each particular field of activity.

Unfortunately, this way of understanding Popper's philosophical approach is uncommon, although I will not be able to fully defend it here. Instead, let me point out that it tends to be endorsed by those who were closest to Popper. As Boland (1994) explains, it is a 'Socratic view' that can be rather difficult to appreciate, because:

The presumption taken for granted by all followers of the normal view says that we would have to justify our knowledge before we can claim to know anything ... What is most disturbing for Popper's disciples is the presumption that any success in science must be due to a practiced scientific methodology. Again, the disciples take the view that methodology has no more guarantees than a Socratic dialogue.

Cue Bartley, who attempted to formulate a revolutionary epistemological view that has had little impact due to the pervasive nature of the aforementioned assumption in the philosophical community. ${ }^{12}$ Bartley (1962:109-10) sums this up pellucidly, under the flag 'comprehensive rationalism' (which was Popper's original phrase, from The Open Society and its Enemies):

The most common conception of rationalist identity, comprehensive rationalism, combines two requirements. (1) A rationalist accepts any position that can

12 There is a difficult debate to be had about the extent to which Bartley had a decisive effect on Popper's thought, as opposed to the inverse: the focal point of their disagreement is Lakatos and Musgrave (1968). 
be justified or established by appeal to the rational criteria or authorities; and (2) he accepts only those positions that can be so justified ... In the stereotyped way in which it is usually told, the history of modern philosophy focuses attention on a number of basically subordinate questions that arise only if comprehensive rationalism is assumed to be possible. Among these, the most important has probably been: What is the nature of the rational authority or criterion to which a rationalist appeals to justify all his opinions? The various theories of knowledge are functions of the answers philosophers have given to this question. These answers fall into two main categories:

(1) According to the intellectualists (or Rationalists - with a capital "R"), the rational authority lies in the intellect (or Reason). A rationalist justifies his beliefs by appealing to intellectual intuition.

(2) According to the empiricists, the rational authority lies in sense experience. An empiricist justifies his beliefs by appealing to sense observation.

The history of these answers is one of failure.

His solution is remarkably simple, and involves absolutely no appeal to authority, or any slip into arbitrary theory selection. Rather, he invokes the simple idea of assessment of the current state of the ongoing debate, and preference on the basis of that assessment. That is, in so far as there is to be 'faith' in anything, this would be 'faith' in ourselves: but that can hardly be any sort of 'faith', since we don't really have any option on this level. ${ }^{13}$ The core idea is that we can 'step outside' of theories, with respect to any irrational attachment (or commitment) we may have to them. Bartley (1984:215-216) puts it so:

The test statements are intended to be hypothetical, and criticisable and revisable, just like everything else in the system; there is no justification, no proof, no fixed point anywhere. There is nothing "basic" about basic statements. And hence no possibility of dogmatism with respect to them. If such basic statements happen to be incompatible with a theory, then the theory is false relative to them; and they are false relative to the theory. There is no question of theory proving reports wrong, or reports proving theory wrong. Both could be wrong: neither is "basic" ... [O]ne steps outside the positionality of the theory to comment on the state of examination of the theory, treating the theory as an object, not as one's point of view, and oneself coming from beyond the theory ... ${ }^{14}$

But recall the flavour of Van Fraassen's objections to what I have dubbed 'naïve metaphysics': that it involves an appeal to abduction, and the adoption of a very deferent view towards the content of contemporary science. Might all this be summed up by saying that its proponents lack the critical attitude towards scientific theories? What

13 It will not do to disagree by saying we could place faith in 'God's word', or the like, instead. For we would still need to assume (if only implicitly) that we were capable of identifying said word, understanding it, and so forth! In this sense, the pancritical rationalist approach is minimal in so far as 'faith' is concerned, at the very least.

14 Bartley does not, I think, go quite far enough. A theory can be 'false' relative to some basic propositions (expressed by statements, or sentence types, no doubt), yes, but this 'falsity' is in its own turn relative to a particular system of logic. Fallibilism about logic is best understood as a component of 'pancritical rationalism', as is suggested by Miller (1994:90-92). 
Van Fraassen would seem to be after, on the other hand, is closer to a pancritical approach. As he puts it (Van Fraassen, 2002:63):

All our factual beliefs are to be given over as hostages to fortune, to the fortunes of future empirical evidence, and given up where they fail, without succumbing to despair, cynicism, or debilitating relativism.

However, it is entirely unclear what force the 'empirical' in this quotation is supposed to have. Why not simply be willing to change all one's factual beliefs on the basis of future evidence? After all, it cannot be a foundational proposition of empiricism, qua thesis in Teller's sense, that "All evidence is empirical evidence". But if the empiricist is only to allow such a claim to be challenged by (alleged) empirical evidence, then she would be rendering it effectively uncriticisable. Similarly, the intellectualist who claims that no (alleged) empirical evidence is admissible is not going to be persuaded that it ought to be on the basis of an (alleged) intuition. Moreover, why treat a theory (T) that our observations have a reliable character - or are some sort of 'route to knowledge' - any more seriously than a given theory (T2) that some observations are being used to test? Is the suggestion that we should be committed to $\mathrm{T}$, or accept it on faith? That we should dogmatically, or at the very least arbitrarily, accept (some form of) empiricism?

Am I being unfair to Van Fraassen? No, since he makes it absolutely clear that his voluntarism - that required by 'The Empirical Stance' - is to be restricted to 'assessment of evidence and/or the updating in response to what is accepted as evidence' (Van Fraassen, 2004b:187). It is not a part of his empiricism that one be allowed to entertain the idea that there might be non-empirical evidence, so my accusation is that it is based on a fundamental bias about what counts as evidence. Van Fraassen (2004b:181) writes: '[O]nly if a theory has empirical import it is subject to test' . But this is clearly false, since a theory can be tested, and found wanting, on the basis of non-empirical features such as internal logical inconsistencies, its failure to provide a solution to the problem that it was designed to address, or external inconsistencies with other theories in nearby domains. The incompatibility of special relativity and quantum theory is non-trivial.

Again, he writes, 'As in science, so in philosophy: disagreement with any admissible factual hypothesis is admissible', yet that this does not come from tolerance, but instead 'pertains quite narrowly to factual truth and error' (Van Fraassen, 2004b:185). But to reiterate, why should non-empiricists need to attempt to convince an empiricist by using only what that empiricist takes to be admissible? That is, by proffering immanent criticism alone? Will the empiricist do the intellectualist an equivalent favour, and not rely on any empirical evidence whatsoever, in advancing her arguments against intellectualism? Surely not, and for a rather simple reason: in discussing what means of criticism are admissible, we cannot presuppose that only particular means of criticism are admissible! And surely a non-dogmatic empiricist does want to be able to take part in such a discussion? ${ }^{15}$

Is pancritical rationalism compatible with voluntarism, though? My answer is in the affirmative, since it arose through Popper's voluntarism. First, a bold hypothesis is perfectly permissible, according to the view that it is context of justification, rather than

15 I cannot make it my business to defend pancritical rationalism here, but ought to point out that Bartley (1984:120) argues that it is vulnerable to criticism. If it were not, then it would fall foul of his $t u$ quoque, explained in section 2. 
context of discovery, which is important with respect to successful (or rational) inquiry. It is not so much the initial classification of a proposition (or theory) as 'true' or 'false' which matters, but how one deals with (and more importantly is willing to deal with) that classification in the light of criticism. So a 'critical rationalist' in Popper's sense would not agree with the following sort of dictum from mainstream epistemology (Steup, 1997:377): 'Our epistemic duty is to ... suspend judgement about $p$ if our evidence neither supports nor contradicts $p$ '. Notice the affinity with Van Fraassen's (2004b:186): '[P]rinciple of tolerance concerning factual statements ... [that] they all have an initial right to life.'

In fact, this links into Popper's views on probability and (the lack of) confirmation. For while he agreed with Keynes (1921:11) that probability 'In its most fundamental sense ... refers to the logical relation between two sets of propositions ...', he utterly disagreed that 'Derivative from this sense, we have the sense in which ... the term probable is applied to the degrees of rational belief' . Popper (1959:§83) stated very clearly that:

Expressed in my terminology, Keynes's theory implies that corroboration (or the probability of hypotheses) decreases with testability. He is led to this view by his belief in inductive logic ... If what we value most is the securest knowledge available - and if predictions as such contribute nothing towards corroboration - why then may we not rest content with our basic statements?

Indeed, despite the considerable confusion that has often arisen with respect to Popper's corroboration function, it must be noted that he specified a specific domain in which it gives a meaningful value, which is richly suggestive of the significance of a critical attitude: ' $\mathrm{C}(h, \mathrm{e})$ must not be interpreted as the degree of corroboration of $h$ by $e$, unless $e$ reports the results of our sincere efforts to overthrow $h$. The requirement of sincerity cannot be formalized ...' (Popper, 1959:418). Popper rejected the notion that the principle of indifference was a synthetic a priori principle, and would similarly reject the logical component of contemporary Objective Bayesianism, which Williamson (2005b:§13) explains as: 'The agent's belief function $p_{\beta}$ should otherwise [i.e. when empirical evidence is taken into account] be as non-committal as possible.' In fact, this might be explained elegantly by appeal to Teller's notion of epistemic policy, treated in the previous section. Williamson's logical constraint looks like an explicit statement of an implicit policy that is not a prerequisite of rationality, according to either Popper or Van Fraassen.

Finally, it might also be said - perhaps somewhat more controversially - that Popper did not proclaim inductive leaps to be impermissible. Rather, as Settle (1990) emphasises, that Popper rejected any epistemic law such that: one ought not commit to belief in $\mathrm{p}$ unless one is in possession of good reasons for this belief. Echoing Bartley's sentiments, Settle (1990) urges:

Irrationalism becomes a rationally excused alternative, if almost nothing worth believing can be rationally justified. Popper's alternative to the demand that to be rationally tenable our beliefs must be rationally justifiable, is then something of a relief. On his view, a person is rationally permitted to hold views that cannot be rationally justified, provided that they are not rationally prohibited, and provided they are not held dogmatically (uncritically) ... [Popperians] think the point is that inductive inferences are not compelling, so that no one should be thought irrational who refrains from accepting conclusions from them. Other 
people think it irrational not to believe what induction supports, even though induction is non-demonstrative. I find it hard to sympathize with this latter view, hard to locate what it is about inductive arguments that warrants such a demand upon my allegiance. And I agree with Popper that the view seems mischievous. Why should I feel rationally compelled, as opposed to psychologically or physically constrained, to believe what may turn out to be false? And why rationally compelled, as opposed to invited or attracted? If the conclusions of non-demonstrative arguments with true premises could be false, would not that be a reason for refraining from belief, for exercising caution, especially if the price of wrong belief were high?

In short, so-called 'inductive inferences' were simply not forbidden in the sense that one ought never to employ them as heuristics, say in order to generate a hypothesis or two. Far from it, for Popper (1983:80-88) himself offered arguments that were not rationally compelling, as he readily admitted.

\section{Conclusion}

In closing, there are two tentative suggestions that I would like to make. The first is with respect to the problem of the rationality of radical conceptual changes in science, which Van Fraassen takes it to be an important task for any empiricist epistemology to tackle. He writes (Van Fraassen, 2004a:129-130):

$[\mathrm{T}]$ here are such changes. They are so radical that they are characterized by a remarkable historical asymmetry. From the prior position ... the posterior view was absurd and the transition to it possible but incapable of justification ... $[\mathrm{H}]$ ow precisely can we understand the transition as having been in accord with reason?

The underlying presupposition is that, because a transition is unjustifiable, it is therefore irrational. But according to Bartley's view, rationality is linked to criticism, rather than justification, such that the problem with which Van Fraassen struggles does not even seem to arise. It is 'solved', in so far as it is dissolved: such changes are motivated by critical activity, rather than being whimsical.

Second, let me suggest that any non-dogmatic empiricism must be limited in scope, since it otherwise precludes its advocates from engagement with transcendent criticism of empiricism itself. When it comes to discussing empiricism, the non-dogmatic empiricist cannot merely assume that the only admissible evidence is 'empirical', because this is exactly one of the issues that is, implicitly or explicitly, to be discussed. But what is more, she cannot in fact just refuse to admit any alleged 'non-empirical' evidence into the discussion, either. In other words, it is not just what she believes, but how she actually engages in the discussion, that is important. She must have the critical attitude.

What is the upshot of all this, with respect to metaphysics? The answer is simple: to criticise it on the basis that it necessarily involves an uncritical approach, say with respect to contemporary science, is a straightforward error. To criticise it on the basis that its proponents need uncritically assume a particular view of the scope of explanation, or what counts as evidence, is also incorrect. Unsurprisingly, metaphysicians can have critical attitudes, and need not have 'false consciousness' of the sort that Van Fraassen ascribes to them. The God of the philosophers is neither alive nor dead, but in a superposition of states, until we examine it by critical discussion. 


\section{References}

Alston, W.P. 1989. Epistemic Justification: Essays in the Theory of Knowledge (Ithaca: Cornell University Press)

Backhouse, R. (ed.) 1994. New Directions in Economic Methodology (London: Routledge)

Bartley, W.W. 1962. The Retreat to Commitment (New York: Alfred A. Knopf, $1^{\text {st }}$ Edition)

Bartley, W.W. 1984. The Retreat to Commitment (La Salle: Open Court, $2^{\text {nd }}$ Edition)

Beller, M. 1998. 'The Sokal Hoax: At Whom are we Laughing?', Physics Today (Sept. 1998)

Boland, L. 1994. 'Scientific Thinking without Scientific Method: Two Views of Popper', in Backhouse (ed.) (1994), 154-172

Ewing, A.C. 1951. The Fundamental Problems of Philosophy (London: Routledge and Kegan Paul)

Freeman, E. and Skolimowski, H. 1974. 'The Search for Objectivity in Peirce and Popper', in Schilpp (ed.) (1974), 464-519

Garver, N. and Hare, P.H. (eds.) 1986. Naturalism and Rationality (Buffalo, NY: Prometheus)

Gillies, D. 2000. Philosophical Theories of Probability (London: Routledge)

Irvine, I. (ed.) 2005 (Forthcoming): Handbook of the Philosophy of Mathematics, Vol. 9 of the Handbook of the Philosophy of Science (Elsevier)

Keynes, J.M. 1921. A Treatise on Probability (London: Macmillan)

Ladyman, J. 2000. 'What's Really Wrong with Constructive Empiricism? Van Fraassen and the Metaphysics of Modality', Brit. J. Phil. Sci. 51, 837-856

Ladyman, J. 2004. 'Empiricism versus Metaphysics', Philosophical Studies 121, $133-145$

Lakatos, I. and Musgrave, A. (eds.) 1968. Problems in the Philosophy of Science (Amsterdam: North-Holland)

Lakatos, I. and Musgrave, A. (eds.) 1970. Criticism and the Growth of Knowledge (Cambridge: Cambridge University Press)

Lipton, P. 2004. 'Epistemic Options', Philosophical Studies 121, 147-158

Lowe, E.J. 1981. 'Indirect Perception and Sense Data', Philosophical Quarterly 31, 330-342

Lowe, E.J. 1998. The Possibility of Metaphysics: Substance, Identity and Time (Oxford: Oxford University Press)

Macleod, A. 1986. 'Self-interest, Rationality, and Equality', in Garver and Hare (eds.) (1986), 59-71

Miller, D. 1994. Critical Rationalism: A Restatement and Defence (Chicago: Open Court)

Monton, B. and Van Fraassen, B.C. 2003. 'Constructive Empiricism and Modal Nominalism', Brit. J. Phil. Sci. 54, 405-422

O' Hear, A. 1980. Karl Popper (London: Routledge and Kegan Paul) 
Pojman, L.P. (ed.) 1999. The Theory of Knowledge: Classical and Contemporary Readings (Belmont, CA: Wadsworth)

Popper, K.R. 1945. The Open Society and Its Enemies, Volume II: Hegel and Marx (London: Routledge, 1995)

Popper, K.R. 1959. The Logic of Scientific Discovery (London: Routledge, 1980)

Popper, K.R. 1968. 'Remarks on the Problems of Demarcation and of Rationality', in Lakatos and Musgrave (eds.) (1968), 88-102

Popper, K.R. 1970. 'Normal Science and its Dangers', in Lakatos and Musgrave (eds.) (1970), 51-58

Popper, K.R. 1983. Realism and the Aim of Science (London: Routledge)

Psillos, S. 1999. Scientific Realism: How Science Tracks Truth (London: Routledge)

Rorty, R. 2002. 'Review of The Empirical Stance', Notre Dame Philosophical Review, 07.2002. (URL: http://ndpr.icaap.org/content/archives/2002/7/rorty-vanfraassen.html)

Schilpp, P.A. (ed.) 1974. The Philosophy of Karl Popper, Library of Living Philosophers Vol. XIV (La Salle: Open Court)

Settle, T.W. 1990. 'Swann versus Popper on Induction: An Arbitration', Brit. J. Phil. Sci. 41, 3, 401-405

Steup, M. 1997. 'A Defense of Internalism', in Pojman (ed.) (1999)

Steup, M. 2000. 'Doxastic Voluntarism and Epistemic Deontology', Acta Analytica $15,25-56$.

Teller, P. 2004. 'What is a Stance?', Philosophical Studies 121, 159-170

Van Fraassen, B.C. 1977. 'The Only Necessity is Verbal Necessity', Journal of Philosophy 84, 71-85

Van Fraassen, B.C. 1980. The Scientific Image (Oxford: Oxford University Press)

Van Fraassen, B.C. 1989. Laws and Symmetry (Oxford: Clarendon Press)

Van Fraassen, B.C. 1991. Quantum Mechanics: An Empiricist View (Oxford: Clarendon Press)

Van Fraassen, B.C. 2002. The Empirical Stance (New Haven: Yale University Press)

Van Fraassen, B.C. 2004a. 'Précis of The Empirical Stance', Philosophical Studies 121, 127-132

Van Fraassen, B.C. 2004b: 'Replies to Discussion on The Empirical Stance', Philosophical Studies 121, 171-192

Williamson, J. 2005a. Bayesian Nets and Causality: Philosophical and Computational Foundations (Oxford: Oxford University Press)

Williamson, J. 2005b. 'Philosophies of Probability: Objective Bayesianism and its Challenges', to appear in Irvine (ed.) (2005) 